\title{
Uma Nova Metodologia para a Reabilitação Urbana Uma Nova Oportunidade para o Centro Histórico e a Baixa do Porto
}

\author{
Joaquim Fernandes Branco*
}

\begin{abstract}
$\mathrm{R}$ litação urbana na Baixa do Porto, porque o fazemos assim, como chegámos aqui, esperando que da sua leitura se retirem alguns ensinamentos, não só com base nas novas pistas e metodologias ensaiadas, mas também dos erros de análise ou de execução que se cometam. Esta nova metodologia inicia-se em 2002, quando se decide introduzir uma ruptura no modelo de reabilitação urbana que vinha sendo seguido na cidade, com base no Cruarb. Entendeu-se, então, que era necessário criar uma estrutura jurídica, financeira e orgânica que fosse capaz de responder, em simultâneo, a várias desafios: escala na intervenção, celeridade nos procedimentos, investimento privado, gestão rigorosa e transparente.

$\mathrm{O}$ artigo encontra-se dividido em duas partes. A primeira apresenta as principais linhas de análise decorrentes do Estudo Estratégico para o enquadramento de Intervenção de reabilitação urbana da Baixa do Porto, encomendado pela Câmara Municipal ao Departamento de Planeamento Territorial da Faculdade de Engenharia da Universidade do Porto'. Para orientação do leitor, refira-se que o estudo apresenta um conjunto diversificado de resultados ligados entre si, sendo alguns mais orientados para o âmbito espacial do processo de reabilitação urbana, outros para a sua dimensão estratégica, outros ainda para questões complementares de reflexão. A segunda parte decorre do âmbito de enquadramento da criação das SRU (pelo Decreto-Lei 104/2004) e dá conta do processo de constituição da Porto Vivo SRU, dos seus objectivos e formas de actuação.
\end{abstract}

Palavras-chave: Reabilitaçäo e Requalificação Urbana.

\section{Estudo estratégico para o enquadramento de intervenções de reabilitação urbana na Baixa do Porto}

\section{Enquadramento}

Considera-se que as acções de reabilitação do parque edificado, para que possam ser duradouras, devem atender à natureza e à dimensão dos problemas que contribuem para a "degeneração" da área central da cidade do Porto, provocando a sua progressiva ruptura face a padrões correntes de qualidade urbana, e devem, também, saber enquadrar os desafios ou os "contextos de oportunidade" que se colocam à cidade e, em particular, à sua zona urbana central, os quais criam condições para a transformação das actuais tendências de "degeneração urbana".

Esta posição exige que o processo de reabilitação urbana, ou de "regeneração", da Baixa Portuense reconheça a diversidade de factores de ordem económica,funcional, institucional, social e espacial - que contribuem para o seu sucesso. É no reconhecimento dessa diversidade que se deve apoiar a relação entre as estratégias ("o que fazer") e as suas formas de desenvolvimento operacional ("como fazer"), pelo que constitui a questão-chave que informa este estudo.

\footnotetext{
* Economista, Presidente da Comissão Executiva do Porto Vivo, SRU - Sociedade de Reabilitação Urbana da Baixa Portuense, SA. Contacto: sru.joaquim.branco@cm-porto.pt

' O texto segue muito de perto o documento produzido pela FEUP, pelo que será composto em grande parte por excertos quase integrais do referido Estudo Estratégico para garantir uma melhor qualidade da exposição e sem que se introduzam alteraçōes que possam adulterar esse trabalho.
} 
A importância atribuída a esta questão manifesta-se em opções específicas não só ao nível da definição das estratégias mas, também, no quadro da sua operacionalização.

\section{Objectivos}

O Estudo Estratégico apresenta como objectivos centrais:

Enquadrar o processo de reabilitação urbana da Baixa do Porto

Trata-se de contextualizar as condições de intervenção por referência ao conjunto de problemas que atravessam a área, definindo prioridades estratégicas para inverter os processos de degradação do edificado, e de fragilidade social, funcional e económica. Trata-se, também, de identificar as apostas estratégicas para desenvolver dinâmicas de transformação e criar as oportunidades para influenciar de forma duradoura o processo de reabilitação. Com este objectivo pretende-se, por isso, atender aos problemas e às oportunidades que devem informar o processo de reabilitação urbana da Baixa do Porto.

Desenvolver formas operacionais de intervenção

Trata-se, em primeiro lugar, de definir zonas estratégicas de intervenção para enquadrar o "âmbito espacial" do processo de reabilitação urbana e, também, para evitar a proliferação não articulada de "unidades de intervenção" de escala reduzida (quarteirão, arruamento...). Trata-se igualmente de desenvolver programas de acção em áreas estratégicas - os espaços de dinamização da reabilitação urbana - de modo a adequar as intervenções de reabilitação urbana a contextos territoriais específicos, a articular essas intervenções segundo uma lógica de conjunto, e de modo, ainda, a atender a diversos modelos e agentes de intervenção. Com este objectivo pretende-se fazer incidir as acções de reabilitação urbana em espaços onde os problemas se manifestam com intensidade, ou se combinam com dinâmicas emergentes e oportunidades de intervenção que importa desenvolver.

\section{Pressupostos gerais}

\section{Problema ou Oportunidade}

O estudo utiliza de forma indiferenciada os termos "reabilitação urbana" e "regeneração urbana". Esta relativa imprecisão terminológica é indicativa da ambiguidade que rodeia a própria definição do que está em causa, dada a dificuldade de estabilizar um conceito geral de degradação ou de "degeneração" urbana. Está-se perante um estado de "privação" ou de ruptura, face a padrões correntes de qualidade urbana? Ou está em causa uma situação de agravamento de "desvantagens" que compromete o acesso a dinâmicas sustentadas de desenvolvimento urbano?

Estas questões mostram a conotação do conceito com um quadro de referência que ora dá peso aos problemas, ora dá importância a contextos de oportunidade. A integração desta duplicidade constitui precisamente o pressuposto central que informa o estudo.

\section{Visão}

Nestas condições, considera-se fundamental "construir" o processo de reabilitação da Baixa Portuense não apenas em torno de dimensões problemáticas e da sua visibilidade actual, mas também a partir de uma Visão que enquadre, a longo prazo, as grandes apostas para a cidade do Porto e as forças estratégicas, ou os factores de sucesso, para o desenvolvimento da Baixa.

Esta Visão apresenta-se, assim, como um elemento crucial para dar coerência às iniciativas de reabilitação urbana de curto e médio prazo, permitindo reforçar a sua integração temporal e, logo, a sua capacidade de sustentação; para orientar os investidores privados e incrementar parcerias entre os diversos agentes da reabilitação; para conjugar as acções de reabilitação do edificado com iniciativas localizadas de investimento municipal; para definir estratégias de acesso a programas nacionais ou a fontes de financiamento (como as associadas aos Quadros Comunitários de Apoio); e para, finalmente, promover a coordenação entre níveis diferenciados de política urbana.

\section{Reabilitação urbana sustentável}

Considera-se, também, importante que o processo de reabilitação urbana saiba combinar 
objectivos de regeneração física com objectivos sociais e económicos: a sustentabilidade desse processo decorre, também, da capacidade de integração de objectivos diversificados. Como se sabe, nas áreas urbanas degradadas, ou "em desvantagem", manifestam-se os efeitos acumulados (e interactivos) de fenómenos de degradação física, de vulnerabilidade social e de fragilidade económica, que mantêm essas áreas num "equilíbrio em perda" e que dificultam a inversão das tendências instaladas. Precisamente porque a regeneração urbana é um processo difícil, torna-se essencial saber enquadrar as soluções tendo como referência o carácter complexo e heterogéneo do problema, e a dimensão diversificada dos desafios.

\section{Parcerias}

Um pressuposto a salientar é o de ordem organizacional. Tem a ver com os modos de relacionamento entre os vários agentes (públicos e privados) que podem intervir no processo de reabilitação urbana, isto é, com a construção de novas relações e parcerias segundo uma lógica de convergência de interesses, de adequação dos instrumentos às problemáticas em causa, de partilha e transferência de soluções, de mobilização de agentes diversificados para a causa da reabilitação urbana. $\mathrm{O}$ objectivo é minimizar os "custos de transacção", e incrementar a eficácia do processo e a sua durabilidade.

O sucesso de um processo de reabilitação urbana passa pela capacidade de articulação e de coordenação de estratégias diferenciadas (de ordem física, económica, social...) as quais envolvem diferentes agentes com "agendas" também variadas, pela ligação entre diferentes níveis de competências (municipais, centrais, sectoriais...), pela transformação de procedimentos (reduzindo-se, por exemplo, a complexidade dos procedimentos administrativos associados às operações urbanísticas de reabilitação), ou seja, pela capacidade de construção de "redes", horizontais e verticais, ou de novos cenários institucionais. Por isso, considera-se que a capacidade de inovação organizacional deve constituir um desafio a atingir no processo de reabilitação urbana.

\section{Áreas de intervenção prioritária}

Finalmente, há a salientar a dimensão espacial. Os territórios afectados por processos de degeneração urbana podem apresentar, no seu interior, espaços com características diversificadas, de nível físico, social, económico e funcional, nos quais se condensam problemáticas específicas que reclamam modos de acção diferenciados. Daí a importância que actualmente se concede à definição de estratégias de regeneração urbana estreitamente apoiadas numa delimitação clara de "áreas de acção" associadas a unidades de vizinhança ("area-based regeneration").

Considera-se determinante para o sucesso do processo de reabilitação urbana da Baixa Portuense atender à diversidade territorial desta área, o que significa saber focar as iniciativas em contextos espaciais bem delimitados que dêem coerência, equilíbrio e sentido de oportunidade às intervenções.

\section{O diagnóstico}

Os Elementos de Diagnóstico descrevem o estado de degeneração urbana da área em estudo e identificam um conjunto de tendências que, pela intensidade das suas manifestações ou pelas suas características, colocam em relevo dimensões básicas das problemáticas em jogo.

Os Elementos de Diagnóstico que se apresentam referem-se à análise do estado de "degeneração urbana" da área central da cidade do Porto e recorrem à informação produzida em estudos recentes e a resultados dos Censos 2001.

A primeira referência da análise é a totalidade da ACRRU (Área Crítica de Recuperação e Reconversão Urbanística), distinguindo-se, depois, um núcleo histórico, a que correspondem as freguesias de Miragaia, São Nicolau, Sé e Vitória, e um anel central, a que correspondem as freguesias de Bonfim, Cedofeita, Massarelos e Santo Ildefonso.

Os principais eixos do diagnóstico são os seguintes:

- O predomínio da função habitacional dos edifícios e o reconhecimento de uma extensão significativa da não ocupação dos alojamentos;

- A existência de alguns espaços de maior intensidade de usos não habitacionais e o reconhecimento da existência de indicadores de um processo de declínio da base económica do centro do Porto;

- Uma estrutura etária da população residente em envelhecimento, acompanhada do 
aumento da importância dos reformados e das famílias mais pequenas;

- A verificação da existência de importantes contrastes internos nos níveis de qualificação, emprego e desemprego;

- Nos alojamentos, a importância do arrendamento e do nível relativamente baixo das rendas, e a identificação de problemas severos e generalizados de conservação e conforto da habitação.

Identificam-se, portanto, tendências gerais, presentes na ACRRU, mas também elementos relevantes de diferenciação espacial, que podem começar por ser descritos com base na distinção entre um núcleo histórico e um anel central.

No núcleo histórico, com base nos indicadores analisados, reside uma população com uma estrutura etária envelhecida (base e no topo), pouco instruída, com fracos níveis de qualificação profissional e com indicadores de desemprego altos. A população residente diminuiu muito nas últimas décadas mas a densidade populacional continua elevada. As famílias habitam em alojamentos na maioria das vezes arrendados, muitas vezes superlotados e sem as infra-estruturas mínimas de conforto. O parque edificado mostra sinais de degradação física muito intensos, demonstrando a pertinência de um programa de conservação e de reabilitação do património. O abandono do núcleo histórico manifesta-se no número de alojamentos vagos existentes e nos processos de desocupação e degradação registados na última década. No anel central a população residente tem uma estrutura etária sobretudo envelhecida no topo, mas globalmente apresenta níveis de instrução e de qualificação profissional mais favoráveis do que o núcleo histórico. Na década de noventa a perda demográfica e a desocupação funcional são muito expressivas na paisagem urbana. Os níveis de degradação e de abandono dos imóveis também são preocupantes e os indicadores de conforto habitacional nem sempre atingem os mínimos desejáveis. Metade do parque habitacional está arrendado e outra metade é ocupado pelo próprio proprietário.

Se esta leitura constitui uma base importante para a compreensão da problemática, há que ter em conta, também, que a percepção completa de causalidades e de interacções deve ter como referência espacial o concelho do Porto e a própria Área Metropolitana do Porto.

Desenvolvem-se, de seguida, alguns dos eixos fundamentais do Diagnóstico:

Uso dos edifícios:

predomínio da função habitacional

Predominam as construções com raiz tipológica residencial, o que fornece à função habitacional uma relevância central num programa de reabilitação urbana. No núcleo histórico, $71 \%$ dos edifícios são exclusivamente residenciais, valor que se eleva para $82 \%$ no denominado anel central.

Processo de extensão significativa da não ocupação dos alojamentos

Na ACRRU, o número de alojamentos familiares clássicos aumenta quase 3\%, entre 1991 e 2001, diminuindo mesmo no núcleo histórico. No concelho do Porto, registava-se, no mesmo período, uma variação de quase 11\%; na Área Metropolitana do Porto, registava-se uma variação de quase $31 \%$.

No núcleo histórico e no anel central, existiam em 2001 quase dez mil alojamentos vagos, o que correspondia a aproximadamente um quinto dos alojamentos existentes nessa área e a metade do número de alojamentos vagos no concelho do Porto.

Entre 1991 e 2001, o número de alojamentos vagos aumentou consideravelmente: no núcleo histórico, passou de 836 para 1950 (133\% de variação), representando mais de um quarto dos alojamentos existentes; no anel central, passou de 4271 para 7440 (74\% de variação). Em ambos os casos, este é mais profundo que o verificado no concelho do Porto.

Existência de espaços de maior intensidade de usos não habitacionais

O número de imóveis em que grande parte da área útil está afecta a outros fins que não os da habitação é comparativamente mais elevado na área em estudo: localizam-se na ACRRU aproximadamente $31 \%$ dos edifícios do concelho do Porto, mas aproximadamente $68 \%$ dos edifícios principalmente não residenciais do concelho, o que pode ser entendido como indicador da importância das funções económicas (terciárias) aqui desempenhadas. 
Indicadores de um processo de declínio da base económica do centro do Porto

O centro do Porto constitui um espaço relevante do emprego e dos serviços, com uma dotação significativa de equipamentos, oferta comercial e serviços de proximidade que deve ser entendida como uma sua potencialidade.

No contexto da Área Metropolitana, o concelho do Porto tem a maior densidade de emprego (que é 7 vezes superior à da média da AMP). Em termos dinâmicos, porém, o Porto aparece como o concelho que regista a maior quebra da população activa, a maior quebra do emprego total e a maior quebra do pessoal ao serviço das sociedades, num contexto em que todos estes indicadores crescem na Área Metropolitana. É também no Porto que se verificam as maiores taxas de desemprego masculino, feminino e jovem.

Um espaço de relativa elevada densidade populacional, mas em perda demográfica

Em 2001, cerca de um terço da população residente no concelho do Porto residia nesta área central (no núcleo histórico e no anel central, residiam aproximadamente 84 mil habitantes).

$\mathrm{Na}$ década de noventa, o núcleo histórico perdeu sete mil habitantes (mais de um terço da sua população), enquanto que o anel central perdia quase vinte mil (mais de um quinto da sua população). Isto significa que metade das perdas demográficas do concelho do Porto se concentra no anel central.

As perdas demográficas registadas são, em termos percentuais, mais profundas na década de noventa, quando comparadas com as verificadas nos anos oitenta.

Uma estrutura etária significativamente envelhecida

$\mathrm{Na}$ década de noventa, verificou-se uma diminuição da população mais jovem e um aumento da população mais envelhecida. Assim, o envelhecimento da população reflectiu-se no topo e na base da pirâmide etária. Em 2001, a população com mais de 65 anos representa $24 \%$ do total no núcleo histórico e $23 \%$ no anel central, enquanto que no total do concelho o valor correspondente é de $19 \%$. A população com mais de 75 anos representa cerca de $11 \%$ da população residente, enquanto o valor de referência no concelho do Porto é de $8 \%$.

O aumento da importância das famílias mais pequenas

Outro factor de análise importante prende-se com as formas de relacionamento mais estreitas do ponto de vista social dos residentes, isto é, a forma como a população se estrutura em agregados familiares. Genericamente, em 2001, cerca de $60 \%$ das famílias são constituídas por um ou por dois indivíduos, o que corresponde a um aumento da importância deste tipo de famílias.

\section{A importância dos reformados}

A percentagem de população reformada, aposentada ou na reserva é mais alta nas áreas centrais do que no resto do concelho. $\mathrm{O}$ peso deste grupo de população é sobretudo elevado no núcleo histórico, reflectindo também a estrutura etária envelhecida.

Importantes contrastes nos níveis

de qualificação, emprego e desemprego.

No núcleo histórico a população residente empregada apresenta uma estrutura profissional claramente mais desqualificada que a estrutura do anel central ou do perfil concelhio médio.

Os grupos mais qualificados (grupos profissionais 1 - quadros superiores da administração pública, dirigentes e quadros superiores de empresas, e 2 - especialistas das profissões intelectuais e científicas) têm uma fraca representatividade no núcleo histórico (representam aí $11 \%$ do total da população empregada, valores que sobem para $29 \%$, no total do concelho, e $31 \%$, no anel central). Pelo contrário, os grupos menos qualificados estão sobrerepresentados no núcleo histórico. A taxa de desemprego no núcleo histórico é claramente superior à registada no anel central e no concelho do Porto. Verificam-se, também, diferenciações importantes no que diz respeito à incidência do desemprego, num contexto geral em que, recorde-se, o concelho do Porto apresenta taxas de desemprego superiores às da média metropolitana. 
A importância do arrendamento e do nível das rendas e a presença de algumas dinâmicas de transformação neste domínio

As famílias no núcleo histórico residem maioritariamente em alojamentos arrendados (cerca de $80 \%$ das famílias residem em alojamentos arrendados ou subarrendados). É, também, neste conjunto de freguesias que se verifica a presença de uma maior incidência dos casos de subarrendamento, em especial na freguesia da Vitória. Em contrapartida, no anel central verifica-se um equilíbrio entre o arrendamento e a ocupação pelos proprietários.

O contexto dominante no arrendamento é marcado por níveis de renda baixos: no núcleo histórico, aproximadamente metade dos alojamentos arrendados têm rendas inferiores a 35 Euros, e quase três quartos dos alojamentos têm rendas inferiores a 100 Euros.

Problemas de conservação e de conforto dos alojamentos existentes

O estado de degradação física dos imóveis é generalizado e preocupante. Segundo os Censos de 2001, cerca de 85\% dos imóveis no núcleo histórico necessitam de intervenções de conservação nas coberturas, $80 \%$ nas estruturas e $84 \%$ nas paredes e caixilharias exteriores. No anel central, os níveis de degradação física dos imóveis também são muito elevados: cerca de $73 \%$ dos imóveis precisam de intervenções de conservação nas coberturas, $70 \%$ nas estruturas e $75 \%$ nas paredes e caixilharias exteriores. Em ambos os casos, a degradação física dos imóveis é mais intensa que a registada, em média, no concelho do Porto.

Mais de metade dos edifícios da ACRRU (quase 10000 edifícios) podem ser classificados, de acordo com os critérios do INE, como estando em mau estado de conservação. No núcleo histórico, existem cerca 2600 imóveis a necessitar de intervenções de conservação nas coberturas. Destes, 1300 necessitam de reparações consideradas grandes ou muito grandes. No anel central, cerca 11 mil imóveis necessitam de intervenções de conservação, das quais 4695 correspondem a grandes ou muito grandes reparações.

\section{A zona de intervenção prioritária}

A importância da delimitação de uma Zona de Intervenção Prioritária decorre da extensão espacial da Área Crítica de Reabilitação e Reconversão Urbanística (ACRRU) da cidade do Porto, e da consequente necessidade de balizar o contexto espacial do fenómeno de degeneração urbana do centro do Porto. Para o efeito, recorre-se à análise sistemática dos diferentes "territórios" contidos na área da ACRRU, identificando-se, a partir de indicadores diversificados, os vários espaços de diferenciação e de semelhança, bem como a sua relação com variáveis críticas.

Pretende-se que esta zona constitua o contexto para a posterior definição de “Áreas de Dinamização da Reabilitação Urbana" nas quais se devem concretizar todo um conjunto de opções estratégicas e condições específicas de acção.

A definição da ZIP parte da delimitação espacial da ACRRU - Área Crítica de Recuperação e Reconversão Urbanística para o concelho do Porto, nos termos do Dec. Regulamentar $n^{\circ} 11 / 2000$. É fundamentada com base na análise quer de um conjunto de indicadores estatísticos e critérios de agrupamento, e seu tratamento cartográfico, quer das condições de qualificação da área em estudo em função de atributos vários relacionados com os residentes e o tecido edificado.

Apresentam-se, a seguir, os resultados desta análise estruturados segundo dois níveis:

Em primeiro lugar, salientam-se as características de diferenciação espacial presentes no interior da área da ACRRU e definem-se lógicas de agrupamento baseadas em critérios de semelhança. A leitura destes resultados permite isolar áreas contrastantes e proporciona as bases para a delimitação criteriosa da Zona de Intervenção Prioritária.

Em segundo lugar, elabora-se uma proposta de delimitação espacial da Zona de Intervenção Prioritária, a qual é formulada numa perspectiva de integração de condições problemáticas ou de espaços em risco de "degeneração urbana", com contextos de oportunidade. Dedica-se, por isso, particular atenção à análise das condições de ajustamento da ZIP a critérios e indicadores relevantes.

Do ponto de vista dos objectivos fundamentais associados à definição da ZIP, esta proposta permite:

- Adequar a natureza de "área crítica de reconversão e de recuperação urbanística" a contextos efectivos de "degeneração urbana"; 
- Ter em conta a existência potencial de "Áreas de Dinamização da Reabilitação Urbana" com diferentes perfis, adequadas à diversidade de situações problemáticas presentes na Baixa do Porto;

- Manter a contiguidade de "áreas históricas" e enquadrar as "áreas de frente urbana contínua consolidada";

- Conduzir estratégias integradas de intervenção, combinando por exemplo soluções mais "curativas" com lógicas assentes na inovação e na mudança do perfil de actividades do centro do Porto.

\section{Padrões de diferenciação e de homogeneidade: os diferentes territórios contidos na área da ACRRU}

Como foi referido, procedeu-se à análise de um conjunto de indicadores estatísticos e critérios de agrupamento, e ao seu tratamento cartográfico, os quais constituem elementos de suporte para a definição da ZIP. Procura-se complementar elementos de diagnóstico anteriores, identificar características de diferenciação espacial, relacionar tipologias de problemas, e delimitar situações contrastantes. Para o efeito, desenvolveu-se uma metodologia centrada em técnicas estatísticas de análise factorial e de "clusters", ou classes.

Em geral, deve sublinhar-se que:

- Foram considerados 23 indicadores estatísticos, que caracterizam a ACRRU à escala da subsecção estatística (quarteirão), segundo quatro dimensões: edifícios, alojamentos, famílias e residentes;

- A análise destes indicadores, do ponto de vista da sua interdependência, permitiu sintetizar a informação em subconjuntos de variáveis (factores principais); recorreu-se para isso à técnica de análise de componentes principais;

- O tratamento cartográfico dos factores principais permitiu registar as diferenças espaciais mais significativas existentes na área da ACRRU, ao nível do quarteirão;

- Definiram-se agrupamentos de variáveis baseados em classes homogéneas, a partir dos factores principais e do conjunto original de 23 indicadores;

- O tratamento cartográfico destas classes permitiu identificar as zonas homogéneas mais significativas existentes no interior da área da ACRRU.

A utilização da técnica de análise factorial isolou seis componentes (factores) principais, que explicam cerca de $77 \%$ da informação fornecida pelos 23 indicadores, a saber:

Factor 1 - Envelhecimento e actividade dos residentes (19\% de variância explicada).

Factor 2 - Idade do edificado e condição social dos residentes (16\% de variância explicada).

Factor 3 - Qualidade dos alojamentos (11\% de variância explicada).

Factor 4 - Ocupação dos alojamentos (10\% de variância explicada).

Factor 5 - Idade e dimensão das famílias (6\% de variância explicada).

Factor 6 - Função dos edifícios (6\% de variância explicada).

A principal utilidade da aplicação desta técnica reside na definição de padrões de diferenciação espacial para a área da ACRRU. Por seu lado, a análise de "clusters", realizada para os dois conjuntos de variáveis referidos anteriormente, permitiu definir lógicas de agrupamento baseadas em critérios de semelhança, e, a partir destas, os padrões de homogeneidade espacial para a área da ACRRU.

\section{A visão}

A Visão e Forças de Estratégia constitui a referência central para orientar a reabilitação urbana no centro do Porto. Contém indicações sobre os factores de qualificação, de atractividade e de relacionamento da zona central da cidade, e define as linhas de intervenção estratégicas a desenvolver. Representa um cenário prospectivo, sustentado na realidade, que procura dar consistência e força estratégica aos recursos existentes e salientar os problemas que têm de ser resolvidos. Desenvolvendo uma perspectiva a longo prazo do centro do Porto, procura, também, dar coerência às iniciativas de reabilitação urbana de curto e médio prazo, e garantir a sua capacidade de sustentação.

O projecto de regeneração urbana do centro do Porto integra-se num modelo de cidade que se quer construir. As iniciativas que vão ser tomadas a curto prazo vão estar correlacionadas com uma 
visão de conjunto a médio prazo. Por outro lado, esta estratégia também pressupõe a necessidade de articular lógicas de intervenção física com necessidades de regeneração social e económica, de forma a obter-se o máximo de benefícios do projecto. De forma a garantir uma melhor operacionalidade da intervenção organizou-se este projecto em seis linhas de intervenção, que devem ser coordenadas e integradas:

A cidade é residência, é qualidade de vida.

A cidade é criatividade, é identidade e inovação.

A cidade é comércio e serviços, é intercâmbio.

A cidade é turismo, é atractividade.

A cidade é interacção, é convivência e governabilidade.

A cidade é edificação, é recuperação urbana.

\section{A cidade é residência, é qualidade de vida}

O centro da cidade do Porto tem de ser em primeiro lugar um espaço habitável, que integra uma estrutura social heterogénea, que usufrui de uma forte centralidade e monumentalidade, que promove o desenvolvimento de laços de sociabilidade e apropriação urbana e recria um espaço de vida diferenciador e integrador.

\section{A cidade é criatividade, é identidade e inovação}

O centro da cidade do Porto constituir-se-á como um espaço atractivo e com grande vitalidade, onde as actividades culturais e as indústrias criativas constituirão um importante factor de atracção de novos residentes, visitantes e negócios, contribuindo para a renovação da economia da cidade, para o reforço da sua identidade e para conferir a este espaço uma imagem de vitalidade, criatividade e diversidade.

\section{A cidade é comércio e serviços, é intercâmbio}

O centro da cidade do Porto é o local do intercâmbio, é a grande praça ou o grande mercado da cidade, é o centro do consumo e da vivência urbana, é o lugar de permuta de ideias e de troca de produtos e de serviços.

\section{A cidade é turismo, é atractividade}

O centro da cidade, como espaço que melhor traduz a identidade e a história do Porto, será um lugar apelativo e distinto, capaz de surpreender os visitantes e de lhes proporcionar experiências únicas e diversificadas, ancoradas na sua riqueza patrimonial e arquitectónica, nas tradições e culturas vivas, na tipicidade da sua paisagem urbana e na população hospitaleira.

\section{A cidade é interacção, é convivência e governabilidade}

O centro da cidade, como espaço de centralidade, de fluxos e de projectos, tem de possuir um sistema de infra-estruturas e de inter-relacionamentos que funcione. Recriar o centro da cidade depende da qualidade e fluidez das infra-estruturas físicas e dos espaços colectivos, mas também da capacidade e da inovação institucional que for impressa ao projecto.

\section{A cidade é edificação, é recuperação urbana}

A recuperação do edificado, é um objectivo económico porque contribui para uma melhor eficiência da cidade-competitiva, evidencia um objectivo social porque evita a exclusão e a segregação, traduz um objectivo ecológico porque recupera um património e afirma um objectivo cultural porque recria uma identidade urbana.

\section{Contextos de dinamização de reabilitação urbana}

Os Contextos de Dinamização da Reabilitação Urbana representam espaços prioritários ou estratégicos do ponto de vista da reabilitação da Baixa do Porto. São definidos através de um conjunto de critérios que têm em atenção as questões identificadas no diagnóstico, a intensidade e a variedade dos problemas presentes na Baixa, as dinâmicas de transformação em curso ou potenciadas pelas estratégias definidas na Visão, e os efeitos da "visibilidade" de intervenções de reabilitação. É com base nestes critérios que se procede à delimitação de "áreas urbanas sensíveis", de "áreas de oportunidade" e de "espaços de singularidade", de cuja sobreposição resulta a definição de vários contextos espaciais para a dinamização da reabilitação urbana.

Para cada ADRU (Área de Dinamização da Reabilitação Urbana) e EDRU (Eixo de Dinamização da Reabilitação Urbana), elaborou-se: 
- Uma definição geral da estratégia a desenvolver, sintetizando as principais mudanças a operar em cada território;

- Um conjunto de sugestões programáticas, orientadas para a reversão dos problemas identificados e para a concretização das oportunidades associadas à "visão";

- Uma identificação das principais articulações estratégicas a ter em conta, necessárias para a criação de condições mais favoráveis à reabilitação do edificado e necessárias, também, para a continuidade, no tempo, das dinâmicas que se pretendem desenvolver;

- Um resumo do diagnóstico de cada ADRU.

As propostas apresentadas têm em atenção as problemáticas associadas a cada um dos espaços. Resultam, também, no entanto, de algumas preocupações comuns, que se sublinham:

- A importância da especificidade de cada espaço, mas também a importância da articulação entre diferentes territórios do centro do Porto;

- A importância da habitação, numa perspectiva diversificada e inclusiva, que tenha em conta:

- a criação de condições gerais para a residência das famílias e dos diversos grupos sociais;

- a atenção a grupos específicos que constituem uma população mais mobilizável para a residência nos espaços centrais da cidade;

- a intervenção nos contextos habitacionais mais problemáticos, articulada com a transformação das condições de vida dos actuais residentes;

- A importância da introdução de factores de inovação, entendendo-a num sentido alargado, que engloba as diversas actividades e as instituições;

- A abertura a diversos modelos, "escalas" e agentes de intervenção;

- A preocupação com a identificação de articulações estratégicas entre as intervenções e os agentes da reabilitação do edificado e as intervenções e os agentes envolvidos noutros domínios de actuação.

A opção pela escolha das ADRU e EDRU pretende, como foi dito, orientar a atenção dos diversos agentes, encontrar espaços de convergência de intervenções diversas. Não significa, no entanto, que o restante território da ZIP (Zona de Intervenção Prioritária) deva ser excluído das preocupações com a reabilitação urbana. Este continua a ser um campo importante de iniciativa individual e de acção dos actuais proprietários e, por parte do município, das intervenções mais gerais de incentivo ou de regulação (através do sistema de licenciamento, da utilização e adaptação dos diversos mecanismos de apoio, da difusão da informação sobre os mercados e sobre "boas práticas" de reabilitação).

\section{Condições complementares de intervenção}

Nas Condições Complementares de Intervenção dedica-se especial atenção a duas questões directamente associadas à reabilitação do parque edificado: a Mobilização de Agentes e o Uso de Incentivos. Assim, apresenta-se, em primeiro lugar, uma reflexão sobre dificuldades de investimento no edificado, com base em estudos comparados e nos resultados de entrevistas a agentes interessados no processo de reabilitação da Baixa. Esta análise permite identificar sugestões operacionais que devem ser tidas em conta na definição, em concreto, dos modelos de acção de forma a mobilizar diversos agentes para o processo de reabilitação urbana. Em segundo lugar, analisa-se o papel de alguns incentivos, de natureza diferenciada, na promoção da reabilitação urbana.

\section{Mobilização de agentes}

Dificuldades de investimento: das possíveis explicações aos possíveis instrumentos de intervenção

As hipóteses apresentadas são úteis para discutir as razões do não investimento no edificado, em determinados espaços, mas também para discutir modelos de intervenção a desenvolver. A cada uma das hipóteses de explicação é possível fazer corresponder sugestões de formas prioritárias de actuação:

- Insuficiência de rendimentos gerados

"se o problema reside na rentabilidade económica do investimento, é necessário actuar sobre as condições que definem essa rentabilidade". Constituem exemplos de instrumentos que 
respondem a esta preocupação a modificação das condições de regulação: dos níveis de renda, dos subsídios de renda, da fiscalidade ou o aumento da intervenção pública no apoio à reabilitação ou na sua promoção directa.

- Incerteza quanto à rentabilidade futura

"se o problema reside na maior incerteza associada a estes mercados, é necessário actuar sobre os principais factores dessa incerteza". Constituem exemplos de instrumentos que respondem a esta preocupação a construção de formas de entendimento estratégico a prazo entre os principais agentes envolvidos, em torno, nomeadamente, da permanência dos mecanismos de apoio ou das regras de transformação urbana; a garantia de parte da procura; outras medidas de controlo da vulnerabilidade ou fragilidade dos mercados associadas à circulação da informação, à concessão de um "prémio de risco", etc.

- Problemas de mediação entre ofertas e procuras

"se o problema reside nas formas de relação entre oferta e procura e nos custos que lhe é associado, é necessário desenvolver mecanismos que actuem sobre essa relação". Constituem exemplos de instrumentos que respondem a esta preocupação a promoção de agências de intermediação, orientadas para os mercados em que estes problemas são mais relevantes, a existência de sistemas de garantias dos contratos.

- Problemas de financiamento da operação

"se o problema reside no processo de financiamento da reabilitação, é necessário construir formas alternativas de organização e gestão desse processo". Constituem exemplos de instrumentos que respondem a esta preocupação a modificação dos planos de financiamento, a transformação nas formas de propriedade dos edifícios, o desenvolvimento de agências - ou fundos - alternativas de financiamento da reabilitação, a actuação ao nível dos mecanismos de garantia dos empréstimos, etc.

- Comportamento expectante dos proprietários

"se o problema reside nas estratégias expectantes dos proprietários, é necessário penalizar este tipo de estratégias". A penalização fiscal deste tipo de estratégias constitui um exemplo de intervenções que correspondem a esta preocupação.

- Dificuldades de gestão das intervenções "se os problemas são do âmbito da programação e gestão das intervenções, é necessário promover e generalizar novas capacidades técnicas de intervenção". Constituem exemplos de instrumentos que respondem a esta preocupação o desenvolvimento de contratos temporários de gestão do parque privado, processos de substituição dos proprietários na organização e gestão da reabilitação, a criação de agências vocacionadas para a manutenção dos alojamentos, a difusão de "guias de boas práticas", estratégias dirigidas para a indústria de construção e para a investigação dos processos de transformação do edificado, etc.

- Dificuldade de adequação da oferta à procura potencial

"se existem factores que dificultam a construção de uma oferta adequada à procura, é necessário promover intervenções que os possam controlar ou conter". Constituem exemplos de instrumentos que respondem a esta preocupação intervenções de reorganização da estrutura da propriedade, esquemas de provisão colectiva de serviços - por exemplo, estacionamento, segurança; adaptação das regras de transformação do edificado.

- Aspectos relacionados com a organização das políticas (locais ou nacionais)

"se existem factores institucionais que provocam desvantagens específicas para determinados tipos de habitação ou de espaço, é necessária uma reorientação das políticas e do funcionamento das instituições". Constituem exemplos de instrumentos que respondem a esta preocupação acções de harmonização dos diversos instrumentos de política habitacional, reorganização dos processos de desenvolvimento do solo e das suas formas de controlo, alteração dos procedimentos das instituições).

\section{Resultados das entrevistas realizadas}

Apresenta-se uma leitura, necessariamente sintética e selectiva, dos resultados de um inquérito realizado a potenciais investidores, organizada em torno dos seguintes pontos:

- o diagnóstico geral da Baixa do Porto, seus problemas e oportunidades mais gerais;

- a explicação mais pormenorizada da situação e sugestões de actuação apresentadas;

- as referências aos agentes e modelos de intervenção a privilegiar. 
- Diagnóstico geral da Baixa do Porto

- A percepção de um contexto difícil ou de uma conjuntura "delicada" (foram várias as referências a "estagnação", "abandono"). Por um lado, reconhece-se que o aprofundamento, ao longo do tempo, dos problemas existentes pode constituir um factor inibidor do investimento na reabilitação. Por outro lado, reconhecem-se algumas possíveis oportunidades: existe, neste momento, capacidade construtiva "abundante"; ao mesmo tempo, as mudanças em curso nos mercados imobiliários parecem apontar para a necessidade de reorientação do investimento e de redefinição dos produtos.

- Uma imagem do centro do Porto que reconhece a relevância da habitação, e que salienta também a importância da mistura de actividades.

- O reconhecimento de questões problemáticas relacionadas com a habitação e seu contexto urbano: estacionamento, segurança, qualidade ambiental. A sua resolução é considerada uma condição da atractividade da Baixa como espaço de residência.

- Explicação da situação e sugestões apresentadas

- A relevância conferida às questões institucionais. Referiu-se a necessidade de introdução de melhorias significativas neste domínio. Foi salientada: a importância do sistema de licenciamento e, em particular, dos prazos para obtenção de licenças (que constituem um elemento importante para o cálculo da rentabilidade das intervenções); foi salientada, também, a importância da articulação entre as diversas entidades envolvidas no processo de licenciamento. Neste sentido, algumas sugestões foram apresentadas: a incorporação das diversas entidades desde o início do processo (incluindo os momentos de planeamento estratégico); a clarificação e publicitação dos critérios de aprovação dos projectos, incluindo os que se relacionam com a definição e salvaguarda do valor patrimonial do edificado.

- A relevância conferida a algumas disposições da regulamentação da construção. Referiu-se, por um lado, a importância da adequação das diversas disposições regulamentares às características específicas da Baixa do Porto e, por outro lado, a importância da garantia da qualidade dessa adequação.

- A relevância conferida à incerteza nos mer- cados e às questões do financiamento das intervenções. Para além das referências à "estagnação" dos mercados, foram muitas vezes reconhecidas a grande heterogeneidade dos preços e as dificuldades na obtenção de informação sobre transacções, efectivas ou potenciais.

- A relevância conferida à difusão dos instrumentos de apoio existentes e à sua adequação ao contexto da Baixa. Algumas sugestões apresentadas, neste domínio, dizem respeito: à promoção de estratégias activas de difusão da informação sobre os mecanismos de apoio existentes; à existência de esquemas de atendimento e aconselhamento, capazes de articular os diversos circuitos do apoio à reabilitação.

- A relevância conferida à gestão dos espaços e das actividades. Para alguns agentes entrevistados, a promoção da atractividade da Baixa do Porto (por exemplo, nas "fileiras" relacionadas com a cultura, o conhecimento ou o turismo) não depende apenas das intervenções no edificado ou da criação de novos espaços para essas actividades.

- Referências aos agentes e modelos de intervenção

A variedade de pontos de vista reflecte-se no modo como os agentes encaram a questão da "escala" da intervenção, as relações com os actuais proprietários, as funções dos edifícios a privilegiar ou, ainda, alguns aspectos da economia e da técnica das intervenções.

Alguns agentes consideram o quarteirão um contexto interessante para a actuação. Valorizam nele a escala (mencionando, por exemplo, valores em torno dos 50 a 100 alojamentos como indicação da dimensão a privilegiar) e a possibilidade de resolver alguns problemas associados à Baixa do Porto (em particular, o estacionamento, mobilizando para isso o interior dos quarteirões ou dedicando-lhe o espaço de um edifício ou conjunto de edifícios).

Outros agentes trabalham, sobretudo, em contextos de menor dimensão. Valorizam menos a escala e consideram interessantes modelos baseados na negociação entre proprietários e construtores (por exemplo, os casos em que a reabilitação é paga com o acesso, pelo construtor, a algumas fracções do edifício).

Entre um e outro caso, foram mencionadas outras possíveis soluções organizativas. É o caso de esquemas de associação e perequação entre 
proprietários. A sua viabilidade depende da identidade dos proprietários existentes e requer a construção de capacidades organizativas várias. É, também, o caso de esquemas baseados na intervenção de cooperativas ou de associações (e na procura de novos agentes do investimento ou da gestão do edificado da Baixa).

- Incentivos à reabilitação urbana

A promoção dos processos de reabilitação urbana tem-se apoiado no uso de incentivos de natureza diversificada, que procuram estimular e orientar as decisões dos vários agentes ou investidores para a estratégia de reabilitação definida.

A questão da relação entre incentivos e reabilitação urbana na Baixa Portuense torna-se importante por duas razões fundamentais. Desde logo, porque a utilização de benefícios representa um processo através do qual se pretende captar, ou atrair, o investimento imobiliário para iniciativas de reabilitação do edificado, em zonas específicas. Está em causa, portanto, uma estratégia de reorientação espacial do investimento imobiliário.

No caso do Porto este aspecto torna-se especialmente crítico:

- por um lado, porque se observam, no conjunto do território da cidade do Porto, tendências importantes de configuração de novas dinâmicas imobiliárias, apoiadas em estratégias de investimento no espaço público, em torno de áreas específicas (o eixo da Boavista, a zona afecta ao Plano de Pormenor das Antas) que, por isso, se apresentam como "espaços" de competição efectiva face à zona central da cidade;

- por outro lado, porque há que ter presente a contínua capacidade atractiva exercida pelos concelhos envolventes da cidade, cujos reflexos na diferenciação centro-periferia do investimento imobiliário e no declínio populacional da cidade central são por demais conhecidos.

A segunda razão para atender à relação entre incentivos e reabilitação urbana na Baixa Portuense centra-se na necessidade de mobilizar outros sistemas de agentes - como sejam os proprietários actuais (residentes ou não) e os inquilinos - para o processo de reabilitação, associados a intervenções de pequena escala. Ou seja, o problema já não é de competitividade espacial ao nível de captação de investimento, mas de capacidade de desenvolvimento de iniciativas de âmbito mais localizado. A dimensão crítica do estado de degradação do edificado, e a sua densidade de ocupação, cruzam-se com a necessidade de envolver uma estrutura localizada e diversificada de agentes e de atender a intervenções de reabilitação muito desiguais (conservação, alteração, reconstrução...). Pode dizer-se, ainda, que a importância desta questão também decorre da anterior: a geração de novas oportunidades para o investimento imobiliário em outras áreas da cidade (Boavista, Antas...) induz, ela própria, a necessidade de saber "construir" a reabilitação da Baixa a partir da mobilização do sistema de agentes locais.

\section{A prática da Porto Vivo, SRU}

\section{Constituição da Porto Vivo, SRU}

Em Novembro de 2004 foi constituída a Porto Vivo, SRU tendo como accionistas o Estado, através do INH, detentor de $60 \%$ do capital e a Câmara Municipal do Porto de 40\%, justificando-se tal repartição pelo dimensão e complexidade do problema de degeneração existente no centro histórico e na Baixa do Porto. A este problema não são alheias as erradas políticas tomadas ao longo de décadas pela Administração Central, as quais terão mesmo sido as principais responsáveis por essa situação, ao "congelar" as rendas a partir de 1948 para a cidade do Porto, ao centralizar o poder de decisão em Lisboa, para aí atraindo e concentrando as principais empresas e sectores de actividade económica, ao adiar, até há poucos anos, a instalação da rede de Metro no Porto, ao permitir a deslocalização de grandes investimentos em equipamentos públicos, designadamente várias Faculdades, para a periferia, ao viabilizar grandes superfícies comerciais nos limítrofes da cidade.

\section{Âmbito geográfico}

Dada a complexidade e diversidade do problema da ACRRU, foi definida, através de uma análise multicritérios, como se referiu, uma Zona de Intervenção Prioritária (ZIP), onde a Porto Vivo, SRU centraliza os seus esforços. 


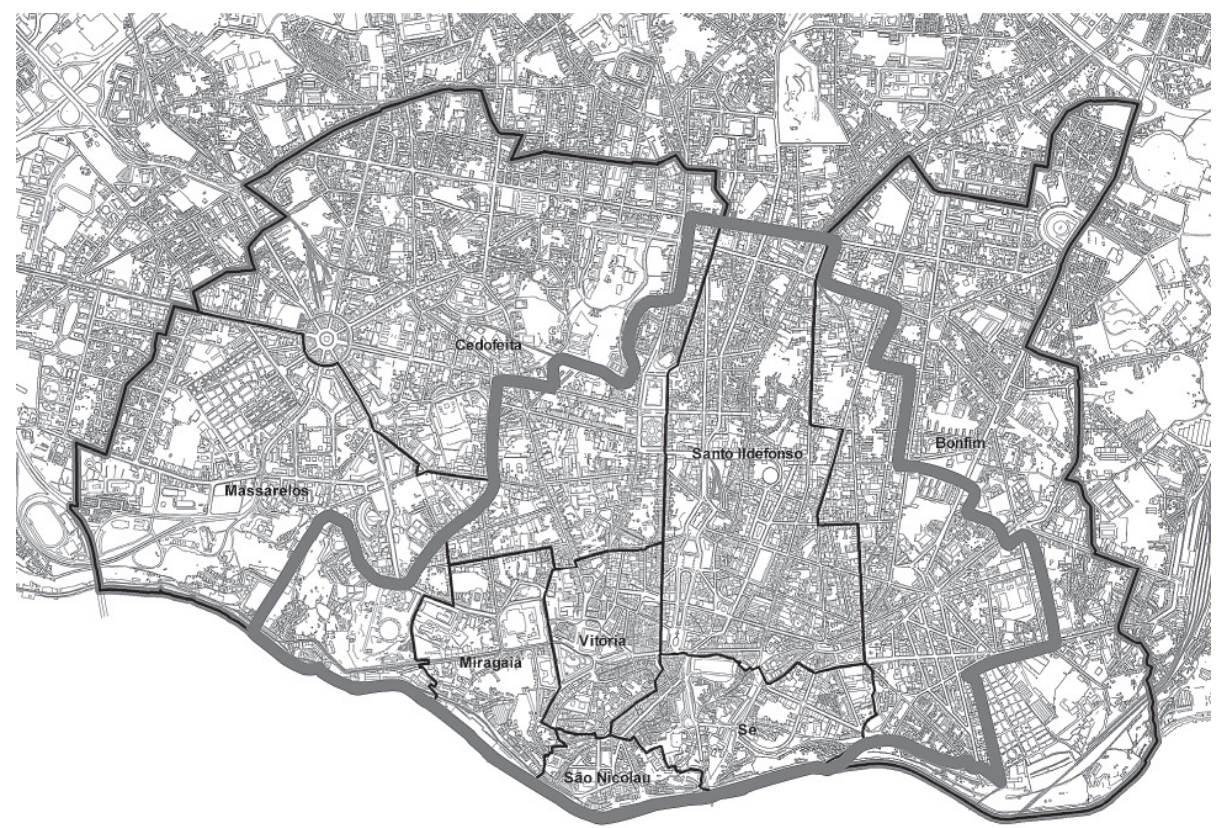

Figura I - Zona de Intervenção Prioritária e área crítica de recuperação e reconversão urbanística

A ZIP conta com 500ha, o que representa cerca de $50 \%$ da área da ACRRU e integra as quatro freguesias do Centro Histórico, bem como uma parte substancial das freguesias que representam os territórios da expansão urbana dos séculos XVIII e XIX.

\section{Planeamento estratégico}

Ao longo de 2005, desenvolveram-se os trabalhos que conduziram à realização de um Plano Estratégico da Reabilitação Urbana da Baixa Portuense, designado de Masterplan, que enquadra todo o processo e no qual estão vertidas as políticas de uma reabilitação que se pretende sustentável, e a sua aplicação territorializada, a par das definições das prioridades e das parcerias a encetar. O Masterplan tem como objectivo último conceptualizar e implementar um Contrato de Cidade, que oriente quem gere e intervém, vincule as entidades tutelares e comunique uma estratégia aos investidores, cidadãos e agentes.

A cidade, e designadamente o seu centro, assume-se como um sistema de múltiplas dinâmicas, simultaneamente distintas e complementares entre si. É o conjugar dessas diversas premissas que podem promover a mudança da realidade face ao diagnóstico realizado. Assim, no Masterplan estabeleceram-se cinco vectores de actuação para a Zona de Intervenção Prioritária:
- RE-HABITAÇÃO, nomeadamente através de uma nova política de habitação, criando condições preferenciais no apoio aos proprietários e aos moradores, de modo a promover a instalação de famílias no centro da cidade;

- DESENVOLVIMENTO E PROMOÇÃO DO NEGÓCIO NA BAIXA DO PORTO, apostando-se na criação de novas empresas, na promoção da investigação, da criatividade, do conhecimento e da inovação, sempre numa lógica sustentada e sustentável;

- REVITALIZAÇÃO DO COMÉRCIO, criando uma estratégia que se apoie na sua identidade, no que de único ele tem face às demais polaridades comerciais existentes, aumentando a sua competitividade e sustentabilidade;

- DINAMIZAÇÃO DO TURISMO, CULTU-

RA E LAZER, com base nas características ambientais e de edificado da cidade, complementadas com a rede cultural e de lazer;

- QUALIFICAÇÃO DO DOMÍNIO PÚBLI$\mathrm{CO}$, actuando a três níveis: a qualificação das infra-estruturas de apoio aos diferentes sectores, a reabilitação dos espaços públicos existentes e a criação de novos e a reorganização da mobilidade, privilegiando o peão e o transporte colectivo relativamente ao privado, apoiando-se nas redes de eléctrico e do metro.

Para além dos cinco vectores de actuação, entendeu-se ainda eleger um conjunto de medidas 
de excepção de abrangência transversal e plurisectorial, que podem ser determinantes para o sucesso da operação. São as designadas ACÇÕES ESTRATÉGICAS (âncoras) que visam os seguintes territórios e domínios:

- Criação de um Parque da Inovação no eixo Campo 24 de Agosto/12 Casas;

- Reconstrução da Avenida da Ponte, uma ruptura física e funcional no interior do Centro Histórico classificado;

- Reabilitação da Frente Ribeirinha, um potencial eixo de lazer e recreio;

- Recuperação do Mercado do Bolhão, um equipamento económico, cultural e de diversão; recursos e vontades, escolheram-se dois eixos estratégicos que induzam fortes dinâmicas de reabilitação, assentes, se possível, simultaneamente em todos os vectores: um eixo norte/sul conformado com o desenvolvimento da cidade ao longo dos tempos e um eixo leste/oeste onde se cruzam as dinâmicas económicas e sociais.

Essas prioridades territoriais foram definidas em 6 Áreas de Intervenção Prioritária (AIP), a desenvolver no período de 2006 a 2011: Infante; Sé/Vitória; Aliados; República; Carlos Alberto; Poveiros / S. Lázaro. Estas 6 AIP envolvem cerca de 2000 edifícios que correspondem aproximadamente a 1300000 m2 de área bruta construída.

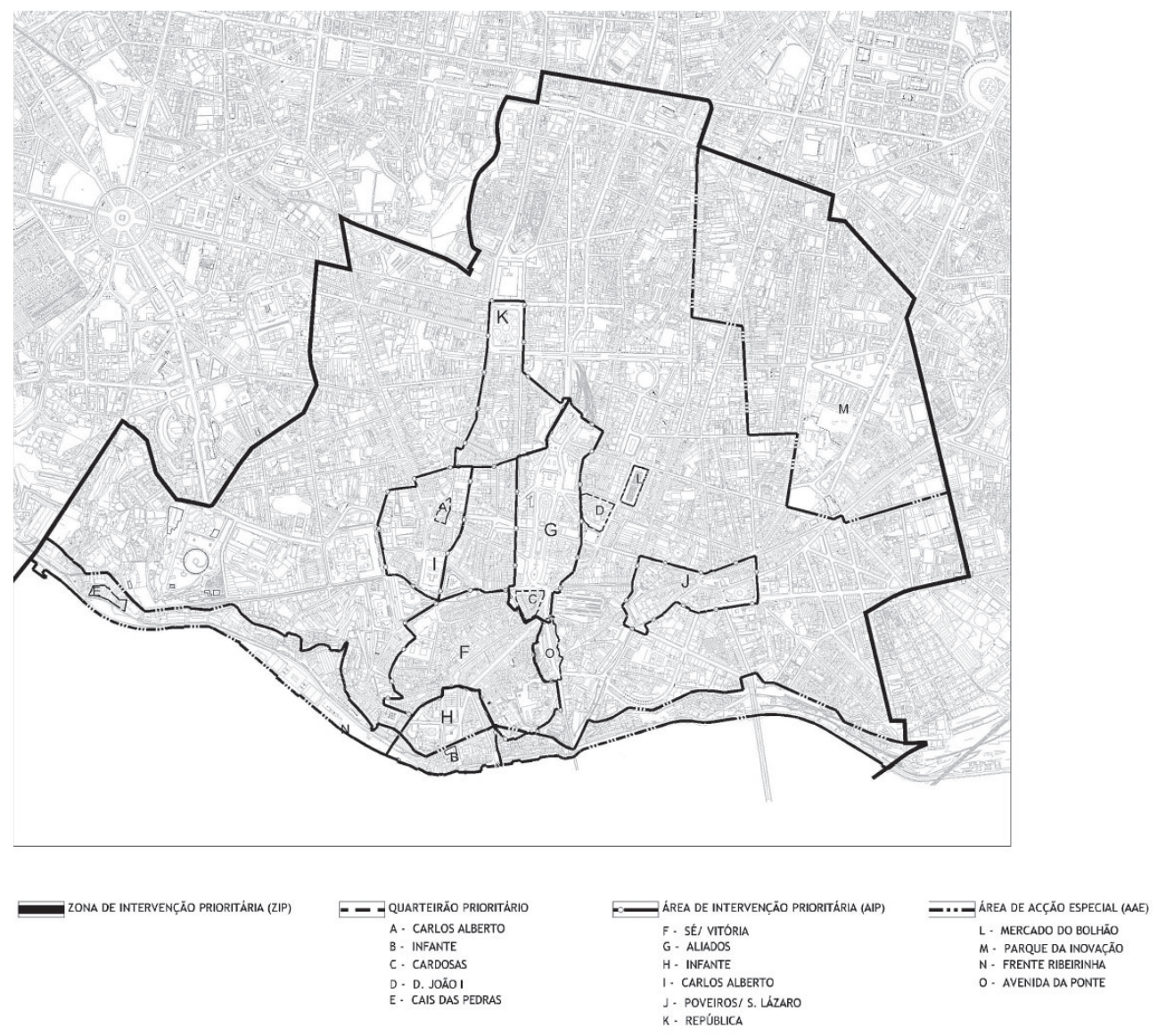

Figura II - Área de intervenção prioritárias, quarteirões piloto e áreas de acção especial

- Instalação da Rede de Eléctrico, um modo de transporte amigo do ambiente e de elevado valor cultural e turístico.

\section{Programa Operacional 2006 a 2011}

Para operacionalizar territorialmente a estratégia, num período que possa mobilizar
Também foram escolhidos cinco quarteirões, apelidados de quarteirões-piloto, para se iniciar a intervenção da Porto Vivo, SRU, possibilitando testar a nova legislação e metodologias de actuação. Os cinco quarteirões foram escolhidos pela sua diversidade de contextos, representando cada um deles uma realidade diferente do que se passa na 


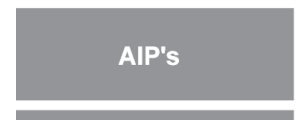

\begin{tabular}{|r|r|r|}
\hline Área Total (A) & \multicolumn{2}{|c|}{ Área Espaço Público (B) } \\
\hline$m^{2}$ & \multicolumn{1}{|c|}{$\mathrm{m}^{2}$} & B/A \\
\hline 120874 & 49124 & $41 \%$ \\
105218 & 39619 & $38 \%$ \\
\hline 204594 & 57303 & $28 \%$ \\
149433 & 75760 & $51 \%$ \\
78656 & 40476 & $51 \%$ \\
88385 & 39870 & $45 \%$ \\
\hline 747160 & 302152 & $40 \%$ \\
\hline
\end{tabular}

\begin{tabular}{|c|c|c|c|}
\hline \multicolumn{2}{|c|}{ Área Bruta Construída (C) } & \multirow{2}{*}{$\mathbf{N}^{0}$ Edificios } & \multirow{2}{*}{$N^{0}$ fogos } \\
\hline $\mathrm{m}^{2}$ & $\mathrm{C} / \mathrm{B}$ & & \\
\hline 171263 & 3.5 & 263 & 660 \\
\hline 165871 & 4.2 & 199 & 648 \\
\hline 395112 & 6.9 & 969 & 3202 \\
\hline 237627 & 3.1 & 216 & 785 \\
\hline 129582 & 3.2 & 203 & 702 \\
\hline 191378 & 4.8 & 248 & 1155 \\
\hline 1290833 & 4.3 & 2098 & 7152 \\
\hline
\end{tabular}

Baixa. Já em 2006, a SRU reabilitou um prédio emblemático na Rua das Flores, que foi um sucesso em termos de técnicas de reabilitação e em termos de mercado, com preços relativamente baixos e com uma procura que excedeu sete vezes a oferta.

\section{Operacionalização no terreno}

Para cada AIP é definido um programa geral de intervenção designado de Estudo Urbanístico, construído com base num levantamento mais "fino" de cada edifício, dos seus proprietários e ocupantes, das suas funções e da sua morfologia, do enquadramento da área no território a nível económico, social, monumental, e das suas carências infra-estruturais, desde estacionamento a espaço público, de tratamento dos resíduos a abastecimentos energéticos. É, então, proposta uma estratégia para a área, consonante com o Masterplan, que é submetida à decisão da Câmara Municipal do Porto, podendo decidir pela dispensa ou pela elaboração de um plano de pormenor.

Após esta fase, inicia-se o trabalho mais envolvente com os proprietários, que de acordo com a legislação é a quem cabe, em primeiro lugar, executar a reabilitação dos edifícios. Efectuam-se as primeiras reuniões, onde se explica o enquadramento estratégico e a totalidade dos passos a dar até à reabilitação integral do quarteirão, onde se inserem os seus prédios, sendo-lhes claramente transmitida a irreversibilidade e a obrigatoriedade do processo, bem como o papel de facilitador e de dinamizador da Porto Vivo, SRU e, ainda, os poderes excepcionais de planeamento, licenciamento, execução, expropriação e de fiscalização de que dispõe.

Apesar de possuírem todos estes poderes, as SRU só os podem exercer após a aprovação do documento estratégico, que é o documento onde se plasma o exaustivo diagnóstico físico, social e funcional dos edifícios, se descreve a estratégia de intervenção no quarteirão, as obras de reabilitação para cada um dos edifícios e a respectiva estimativa orçamental.

A abordagem social do quarteirão inicia-se com a realização pormenorizada de vistorias a todas as fracções, estabelecendo-se as primeiras linhas de intervenção, ouvindo os inquilinos e os senhorios, que acompanham todo o levantamento nos termos definidos na lei. Estes trabalhos são conduzidos por equipas da própria Porto Vivo, SRU, mas realizados por equipas multidisciplinares de ateliers que trabalham agregados à Loja da Reabilitação Urbana, ou, nos casos mais complexos, são executados por gabinetes com quadros muito experientes. As soluções vão sendo discutidas com os proprietários, não abdicando a Porto Vivo, SRU de deixar de introduzir os factores de mudança que no Masterplan se preconizam e de salvaguardar as condições de segurança, conforto, salubridade e estética dos edifícios.

Na proposta procura-se maximizar a dotação de estacionamento, a introdução das infra-estruturas, se possível colectivas, ao nível de energia, de águas residuais e pluviais, de recolha de resíduos sólidos, de definição de regras e técnicas construtivas específicas para a reabilitação. A proposta base de documento estratégico é então submetida à crítica e à recolha de sugestões de todos os interessados por um período de vinte dias úteis. Após essa fase e depois de ponderados os contributos recebidos procede-se à aprovação do Documento Estratégico, que será, de imediato, notificado a cada um dos proprietários, os quais deverão celebrar um contrato de reabilitação com a SRU no prazo de 60 dias. Caso o não façam, a SRU pode substituir-se ao proprietário na execução 
das obras, podendo, sempre que necessário, expropriar o prédio.

\section{Parcerias}

A Porto Vivo, SRU, dada a sua natureza e âmbito de intervenção, tem de permanentemente estabelecer uma forte articulação estratégica e operativa com a Câmara Municipal do Porto, pelo que há um grande intercâmbio na apreciação e licenciamento de projectos, nas intervenções no espaço público, na definição de políticas e regras para as infra-estruturas, bem como há mobilidade de quadros.

A Porto Vivo, SRU definiu no seu Masterplan a necessidade de estabelecer várias parcerias. Para a da energia, a SRU decidiu ser um dos associados fundadores da Agência da Energia do Porto e através dela serão definidas as grandes linhas para cada quarteirão e para cada projecto será emitida opinião. Também com a Portgás foi estabelecido um protocolo que garante o abastecimento de gás natural a todos os prédios e com um apoio financeiro significativo. Para garantir a qualidade dos projectos e da sua execução estabeleceu-se um protocolo com o IEP para a sua certificação. Ao nível das comunicações está estabelecido um protocolo em que se garante que os quarteirões a intervencionar estarão dotados com os mais modernos sistemas. Com os serviços da Câmara Municipal do Porto, das águas e do ambiente, está em curso a definição de um conjunto de princípios a seguir pelos diversos intervenientes: Câmara, SRU, proprietários.

Para a intervenção no edificado e de acordo com a lei é ao proprietário que cabe executar a reabilitação e, na sua ausência, entende-se que não deverá ser a SRU a participar directamente, pois um projecto de mudança deve ser capaz de mobilizar os principais actores da reabilitação, neste caso, os investidores. Daí que a lei preveja a possibilidade de a SRU poder seleccionar, por concurso público, um parceiro privado que ajude os proprietários a reabilitar ou, quando não o queiram fazer, substitua a SRU adquirindo os prédios e realizando as obras por sua conta e risco. O grau de adesão dos investidores a este processo tem sido o melhor aferidor da credibilidade da estratégia e da confiança na sua execução.

Para além dos parceiros já seleccionados por concurso, hoje, já existem vários quarteirões de elevada dimensão e de grande poder de arrasto a ser trabalhados directamente por promotores/investidores, reservando-se à SRU o tal papel de facilitador e de dinamizador do processo.

Há quarteirões para os quais se estão a estabelecer parcerias específicas com cooperativas, no sentido de reter e de atrair população originária em condições económicas e financeiras compatíveis, utilizando como alavanca prédios e incentivos financeiros públicos.

\section{Mecanismos de apoio}

\section{Loja da reabilitação urbana}

Dadas as reconhecidas dificuldades do processo, a Porto Vivo, SRU entendeu ser necessário disponibilizar ferramentas que facilitassem e mobilizassem as intervenções dos proprietários e dos promotores privados. Criou-se a Loja da Reabilitação Urbana (LRU), como front-office da Porto Vivo, SRU, onde se fornece e trabalha a informação para quem quer reabilitar, residir, trabalhar, investir na Baixa. É o local onde se encontram os agentes, onde se conhecem os apoios, as oportunidades e as condições de agilização de projectos.

No âmbito da LRU, a Porto Vivo, SRU celebrou um conjunto de protocolos de parceria com entidades de diferentes sectores, a fim de oferecer serviços que respondessem às necessidades dos agentes. Foi seleccionada uma mediadora imobiliária para estar presente na LRU, para fazer o encontro entre a procura e a oferta de imóveis na Baixa, dando resposta a um mercado em aberto, bem como um conjunto de bancos que oferecem as melhores condições financeiras do mercado.

\section{Programa Viv'A Baixa}

Foi criado o Programa Viv'A Baixa, com o objectivo de diminuir os custos de obra nos imóveis da ZIP, assim contribuindo para dinamizar as operações de reabilitação do edificado. O programa foi montado recorrendo a várias empresas fornecedoras de materiais de construção, negociando-se preços e descontos. O Programa Viv'A Baixa passa ainda por informar sobre projectistas/consultores nas áreas da arquitectura, engenharia e consultoria jurídica, que garantam padrões de qualidade de serviço, cumprimento de normas 
e honorários reduzidos. Para o efeito a Porto Vivo, SRU seleccionou equipas de jovens arquitectos/ /engenheiros/juristas para se instalarem em ateliers da LRU, dinamizando a zona (Bairro da Sé) e criando oportunidades de trabalho para jovens.

\section{Incentivos fiscais}

Na reabilitação de imóveis nas áreas de intervenção da SRU a taxa de IVA a aplicar é de $5 \%$. Esta é uma medida que o governo acedeu a incluir no orçamento de 2007, pois a Porto Vivo, SRU desde a primeira hora sensibilizou os sucessivos governos para a necessidade de criar alguma competitividade com a construção nova, sob pena de se não vencer a inércia.

A Câmara Municipal do Porto também adoptou uma política fiscal favorável à reabilitação urbana ao reduzir em 30\% a taxa de IMI para prédios reabilitados e um agravamento de $30 \%$ para os degradados. Na área de intervenção da SRU a Câmara isenta de taxas de ocupação de via pública e de publicidade as obras de reabilitação, bem como, na quase totalidade das situações, não há lugar a taxas de compensação. O IMT pago em prédios adquiridos para reabilitação poderá ser recuperado se a mesma se efectuar no período de dois anos. Caso o prédio seja adquirido no centro histórico está isento por força da classificação de património da humanidade.

\section{Sim-Porto}

A Porto Vivo, SRU elaborou um regulamento municipal que visa apreciar os projectos de reabilitação com base em critérios específicos, genericamente, assentes na melhoria das condições de habitabilidade. Além disso, esse método de multicritérios concede direitos de construção nova, transaccionáveis no mercado, que acrescem ao índice de edificabilidade fixado em PDM, ganhos em função do número de $\mathrm{m} 2$ efectuados em prédios reabilitados nas unidades de intervenção da SRU.

\section{Financiamento}

Este aspecto justifica só por si um ponto autónomo, mas dado que só a partir de meados de
2007, terá uma maior acuidade, será abordado de forma muito ligeira. A Porto Vivo, SRU definiu um plano de financiamento para o período de 2006 a 2011, para todas as intervenções previstas nas 6 AIP, nas Áreas de Acção Especial, quer ao nível do edificado (no pressuposto de que não haveria parceiro privado), quer ao nível de espaço e equipamento público, que apresentou junto do BEI e que mereceu acolhimento. Está-se também a preparar a apresentação de projectos junto do próximo QREN, pois a visão integrada do projecto de reabilitação urbana, permitirá ter grandes condições de elegibilidade.

\section{Lei das rendas}

Já em 2006, foi finalmente concluído um novo diploma para o arrendamento de prédios urbanos, que veio resolver alguns dos principais bloqueios a um salutar e concorrencial mercado, capaz de gerar novas dinâmicas de reabilitação, apesar de (o futuro o dirá) se prever que ainda não contenha todos os factores de atractividade e mudança célere que era necessário introduzir.

\section{Gestão de área urbana}

A implementação das políticas "imateriais" de reabilitação urbana vão ser objecto de acções mais concretas e vigorosas ao longo de 2007, vitais para a consolidação e sucesso de todo o processo, designadamente ao nível do comércio, com base em planos de urbanismo comercial para as AIP, ao nível do turismo, se possível, com a criação de um Welcome Center de âmbito regional, ao nível da instalação de empresas, dinamizando o parque da inovação, ao nível social, criando rapidamente melhores condições de habitabilidade nos quarteirões críticos e condições de atracção de investimento. A dinamização de todo este processo passará pela criação e lançamento da figura do Gestor da Área Urbana, que articulará a população, os empresários e as instituições em torno das principais estratégias e respectivas acções transversais a uma reabilitação urbana sustentada. 


\section{Bibliografia}

EVANS, Stephen (2003), Porto Sustainable City, Cranfield University, MRes and MSc GROUP Project.

GESTLUZ CONSULTORES (2005) Promoção do negócio na Baixa do Porto, Revitalização do Comércio e Dinamização do Turismo.
HWCA, Gestluz e equipa Porto Vivo, SRU (2005), Revitalização Urbana e Social da Baixa do Porto" - Masterplan.

VÁSQUEZ; Isabel Breda, Paula Conceição, Teresa Sá Marques, Pedro Móia Matos e Frederico Moura e Sá (2004), Estudo Estratégico para o enquadramento de intervenções de reabilitação urbana na baixa do Porto, Universidade do Porto - FEUP - Laboratório de Planeamento do Território e Ambiente. 